\title{
The word-detection effect: Sophisticated guessing or perceptual enhancement?
}

\author{
WILLIAM PRINZMETAL and CHARMAINE E. LYON \\ University of California, Berkeley, Califormia
}

\begin{abstract}
Subjects discriminate letters in words better than letters in nonwords. The sophisticated guessing hypothesis attributes this word advantage to a guessing strategy. In words, the possible letters at each letter position are constrained by letters at other positions, whereas letters in nonwords are not restricted in this manner. A critical test of this hypothesis is that if subjects are given explicit knowledge of the letters in nonwords before the trial, the word advantage would disappear. We investigated the effect of preknowledge of the alternatives in the word-detection effect. In the word-detection effect, subjects decide which of two character strings contains letters and which contains pseudoletters. In four experiments, subjects were more accurate with words than with nonwords, and subjects were more accurate when they were told the word or nonword before the trial. However, even with foreknowledge of the alternatives, subjects were more accurate with words than with nonwords.
\end{abstract}

Many of the most interesting phenomena in contemporary visual information processing and cognition were anticipated by a series of experiments conducted by James McKeen Cattell in the late 1880s (e.g., Cattell, 1885, 1886a, $1886 \mathrm{~b}$ ). These phenomena include the effect of stimulus onset asynchrony on masking, the effect of a warning stimulus on attention, the cross-modal effect of distracting stimuli on attention, the display-size effect, the relation between intensity and duration on perception (Bloch's Law), the effect of an energy mask, the effect of differential confusability of colors and letters on perception, and the effect of familiarity on recognition, to mention a few. ${ }^{1}$ One of Cattell's most noted findings regarded the perception of letters in words and nonwords. Cattell observed that "three times as many letters [can be grasped] when they make words as when they have no connection" (Cattell, 1885, p. 311). The purpose of this paper is to determine whether the advantage for words over nonwords in a contemporary experimental paradigm is caused by perceptual processes, or whether the advantage afforded words is caused by a nonperceptual sophisticated guessing strategy.

Cattell discussed at least one nonperceptual explanation for his finding that subjects could report more letters from words than from nonwords. Cattell was aware of sometimes perceiving a stimulus but then forgetting it $(1885$, p. 312$)$. Short-term memory limitation would favor the report of words over nonwords because subjects would have to remember fewer items with a word than with a nonword. For example, with a five-letter word subjects would only have to remember one word, whereas with a

This research was supported by National Science Foundation Grant 93-19103. We would like to thank Deborah Henderson for her insightful comments on the manuscript. Reprint requests should be sent to W. Prinzmetal, Department of Psychology, University of California, Berkeley, CA 94720 (e-mail: wprinz@garnet.berkeley.edu) nonword consisting of five unrelated letters, subjects would have to remember five separate letters. Reicher (1969) demonstrated that even when the memory load for words and nonwords was equated, subjects were better at reporting letters in words than letters in nonwords. In Reicher's experiment, subjects had to determine which of two alternative letters (e.g., $N$ or L) was present in a briefly presented letter string. Reicher compared performance with words (e.g., WIND), nonwords (e.g., DINW), and single letters (e.g., N). In all three types of stimuli, subjects only had to remember and report one letter. Reicher's procedure also controlled for a second potential nonperceptual factor in Cattell's whole-report experiment. In Cattell's experiment, if a subject perceived the first three letters of a four-letter word (e.g., WIN?) they would probably not guess randomly, but would rather respond with a letter that formed a word (D). In Reicher's experiment, each of the alternative letters formed a word with the word stimuli, so subjects could not use the strategy of guessing a letter simply because that letter formed a word.

Reicher found that subjects were significantly more accurate with words than with nonwords (a string of unrelated letters) and that they were also more accurate with words than with single letters. These two findings have been called the word-superiority effect and the word-letter effect, respectively. Both have been replicated extensively (see Carr \& Pollatsek, 1985, for a review). In this paper, we will be concerned mostly with the word-superiority effect (word vs. nonword comparison) rather than the wordletter effect (word vs. single letter comparison), since the former occurs in a wide variety of circumstances, whereas the latter occurs with a particular kind of visual mask (Prinzmetal, 1992; Prinzmetal \& Silvers, 1994).

An advantage of words over nonwords has also been found in a paradigm called the word-detection effect. Doyle and Leach (1988) asked subjects to decide if a stimulus consisted of a string of real letters, or a mask con- 
structed of pseudoletters (see Figure 2 for an example of pseudoletters). Doyle and Leach found that subjects were more accurate in discriminating real letters from pseudoletter masks when the stimulus consisted of a word than when it consisted of a nonword. This finding has been replicated by both Merikle and Reingold (1990) and Prinzmetal and Silvers (1994). Like the word-superiority effect, the word-detection effect does not have a larger memory load when the stimuli are words than when they are nonwords. Furthermore, in the word-detection effect, subjects are not asked to identify individual letters and so a strategy of guessing letters that form words does not play a role in this paradigm.

Unfortunately, both the word-superiority effect and the word-detection effect have a nonperceptual explanation, proposed by Thompson and Massaro (1973; also see Bjork \& Estes, 1973; Estes, Bjork, \& Skaar, 1974). This explanation has been called sophisticated guessing (Johnston, 1978). The sophisticated guessing hypothesis proposes that on word trials, subjects can use their explicit knowledge of English spelling or the English lexicon to constrain the response alternatives, whereas on nonword trials they do not have this additional source of information. Thompson and Massaro (1973) describe the operation of sophisticated guessing in the word-superiority effect with the following example. Suppose, on a word trial, a subject perceives that the stimulus contains the letters WOR_. For the last letter the subject is only able to determine that the last letter contains the curved feature (i.e., $\supset$ ). Hence the last letter can be either D, Q, or O. Because the subject knows that $D$ is the only alternative that will result in a word, the subject will guess D. On a nonword or a single letter trial, the subject has no reason to choose D over the other two possibilities. Therefore, on two thirds of the trials, the subject "synthesizes" or will decide that the stimulus is a $\mathrm{Q}$ or an $\mathrm{O}$.

Sophisticated guessing can also account for the worddetection effect. Suppose a subject is presented with a four-letter stimulus and has to decide whether it is constructed with letters or pseudoletters. The subject decides that the first, second, and third characters are either the letters WIN or three pseudoletters that are similar to the letters $\mathrm{W}, \mathrm{I}$, and $\mathrm{N}$. The subject will only have to decide whether the fourth character is an D, E, G, K, or S. The number of alternative letters that the subject must consider has been reduced from 26 to 5 . With a nonword, there would be no such constraints. Of course, in the worddetection effect, such decision constraints may operate at any character position, since there is not a specific target character.

Massaro (1973; Thompson \& Massaro, 1973) and Bjork and Estes (1973; Estes et al., 1974) proposed the following critical test of the sophisticated guessing hypothesis. If subjects have explicit knowledge of the possible letter sequences for nonwords as well as for words before the trial, the advantage for words should be eliminated. This prediction is illustrated in Figure 1. Without explicit knowledge of the letter alternatives, performance should be better with words than with nonwords (the word-

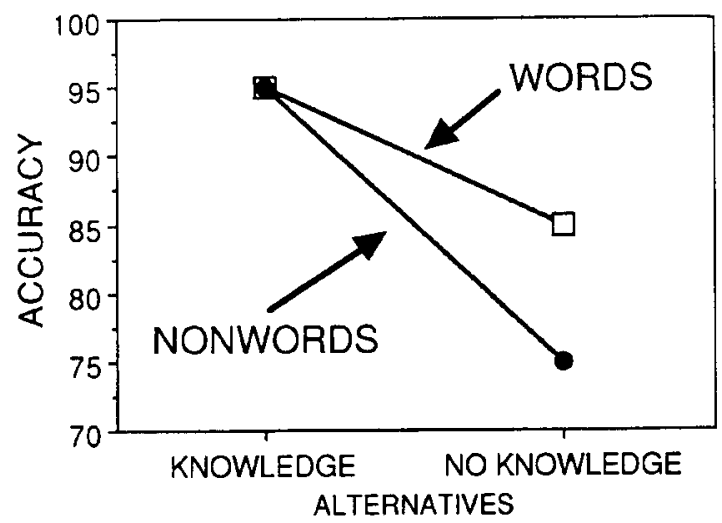

Figure 1. Predictions of the sophisticated guessing hypothesis.

superiority effect). This is because the redundancy in English would constrain the possible letter sequences for words, but there would be no such constraints with nonwords. However, if subjects are given the response alternatives before the trial, and if they use this information, the word advantage should be eliminated because subjects could now constrain the possible response alternatives with nonwords as well as words. In order to test the sophisticated guessing hypothesis, three conditions, i1lustrated in Figure 1, must be met. First, without foreknowledge of the alternatives, performance should be better with words than with nonwords (i.e., a standard word-superiority effect). It is necessary to replicate the standard word-superiority effect because various factors can eliminate it. These factors include too large a visual angle, spaces between letters, or precuing the target position (see, e.g., Holender, 1979; Johnston, 1981; Purcell \& Stanovich, 1982; Purcell, Stanovich, \& Spector, 1978). Second, it is necessary to show that subjects are using the constraining information. It is not sufficient to compare explicit constraint and no-constraint conditions; one must also demonstrate that this information is relevant and is being used by the subject. Finally, if information is provided for nonwords that constrains letter choices, as is the case with words, then the word-superiority effect will be eliminated (see Figure 1).

It should be noted that the present experiments test the notion that explicit information about possible letter sequences would eliminate the word advantage. We do not question the notion that "redundancy" (i.e., various constraints), in some form or other, is responsible for the word advantage. Redundancy can operate at either a perceptual or a decision level. For example, McClelland and Rumelhart (1981) proposed that the feedback from the lexicon affects the activation of letter units. In the Reicher task, the amount of feedback is related to the number of words that share all but one letter with the stimulus (i.e., "neighbors"), and the number of neighbors that contain the target letter (i.e., "friends"; cf. Paap, Newsome, McDonald, \& Schvaneveldt, 1982, for a similar proposal). McClelland and Rumelhart (1981) found that lexical redundancy, measured in terms of the number of neighbors and 
friends, predicts performance in the Reicher task (cf. Johnston, 1978; Solman, May, \& Schwartz, 1981). Richman and Simon (1989) found that redundancy, measured in terms of correspondence to familiar spelling patterns, also predicts accuracy in the Reicher task (also see, e.g., Massaro, Jastrzembski, \& Lucas, 1981; Massaro, Venezky, \& Taylor, 1979; Venezky \& Massaro, 1987). There is no reason why redundancy in these two theories would be affected by explicit information about possible letter sequences. The processes involved could be described as cognitively impenetrable (Pylyshyn, 1980) or encapsulated (Fodor, 1984) in the sense that the word advantage is not dependent on any particular guessing strategy. These theories can be contrasted with the proposal that explicit knowledge of the alternatives would eliminate the word advantage.

The sophisticated guessing theory of the wordsuperiority effect has been tested by Massaro (1973; Thompson \& Massaro, 1973) and Bjork and Estes (1973; Estes et al., 1974) in two different ways. In the first method, the set of possible targets was small and the same on every trial so that subjects knew before each trial that the target would be, for example, either the letter $L$ or the letter R (see, e.g., Bjork \& Estes, 1973). In the second method, the target alternatives changed on each trial but the alternatives were presented before each trial as well as after (see, e.g., Thompson \& Massaro, 1973). In these early experiments, performance with words was not better than performance with nonwords. However, this research collected data on only two of the four conditions illustrated in Figure 1. Specifically, this research did not demonstrate that a word-superiority effect would have been obtained if the alternatives had not been provided before each trial. Furthermore, if the same set of alternatives are used on each trial, there is no way to measure whether subjects are actually using this information. Subsequently, several investigators have demonstrated that a word-superiority effect can be obtained when the alternatives used on each trial are known in advance (e.g., Purcell \& Stanovich, 1982; Purcell et al., 1978; Smith \& Haviland, 1972), but these studies did not demonstrate that subjects actually use preknowledge of the alternatives (see Figure 1).

In his original study, Reicher (1969) changed the alternatives on each trial. In addition, he compared performance when the alternative letters were presented both before and after the stimulus with a condition in which the alternatives were presented only after the stimulus.
The advantage for words over nonwords was approximately equal in both conditions. However, Reicher found that performance was actually worse when subjects were given the alternatives before and after the stimulus than when they were given the alternatives only after the stimulus was presented. This difference in performance was true for words, nonwords, and single letters. Subjects were not using information about the response alternatives to improve performance in any of the conditions. The finding that performance is worse when the alternatives are known in advance of the stimulus has been replicated several times (e.g., Neill, 1985; Smith, Reder, Haviland, \& Brownell, 1976). Smith et al. hypothesized that the "before disruption" effect might have been due to subjects' mistaking features in the mask for one of the targets that they were searching for. (See Dixon, 1986, for a related phenomenon that does require a mask.) In any case, since Reicher did not find any advantage for presenting the alternatives before the stimulus, subjects were probably not using this information to constrain their responses in the word, nonword, or single letter conditions. Thus this negative result cannot rule out the possibility that more effective constraints might eliminate the wordsuperiority effect.

It appears that the Reicher (1969) paradigm presents several problems for testing the sophisticated guessing hypothesis. On the one hand, if the same alternatives are used on each trial, one cannot compare performance with knowledge of the alternatives to performance without knowledge of the alternatives. On the other hand, if the alternatives are changed from trial to trial, one can compare presenting the alternatives before and after the stimulus with presenting the alternatives only after the stimulus. However, because of the "before disruption effect," subjects are usually worse when they are presented with the alternatives before the stimulus. Because of the problems inherent in the Reicher paradigm, we turned to the word-detection effect to test the effect of foreknowledge of possible letters on the advantage for words over nonwords.

Our experiments were patterned after those of Prinzmetal and Silvers (1994). On each trial, subjects were presented with two rectangles. One rectangle contained a string of letters, and the other contained a string of pseudoletters (see Figure 2). The subject's task was to indicate which box contained the letters. On half of the trials, the letters spelled an English word, and on half of the trials, the letters formed a nonword (i.e., a random
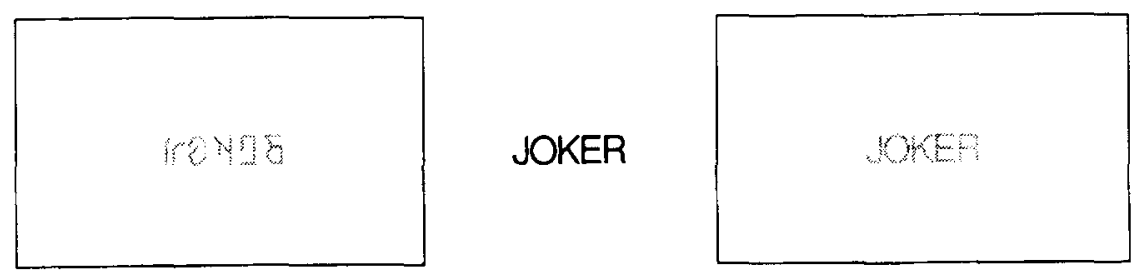

Figure 2. Sample word stimulus from Experiment 1. 
string of letters). The stimuli were rendered difficult to perceive by reducing the contrast of the letters and pseudoletters. Subjects had as much time as they wanted in order to respond, and accuracy was the dependent variable. Prinzmetal and Silvers found that subjects were more accurate when the letters formed a word than when they formed a nonword.

The present experiments differ from those of Prinzmetal and Silvers (1994) in that on half of the trials, subjects were shown the word or nonword between the two rectangles at full contrast (see Figure 2). We call these trials hint trials. On hint trials, subjects knew exactly what letters were possible in each letter position. If the worddetection effect that we previously observed was due to the fact that subjects could constrain the letter possibilities on word trials, then informing subjects of exactly what letters to expect should cause nonword performance to be as good as word performance. Thus, according to the sophisticated guessing hypothesis, the word advantage would be eliminated on hint trials. In addition, if subjects are profitably using the information provided on the hint trials, they should be more accurate overall on these trials than on the no-hint trials. Only by demonstrating (1) a word advantage on no-hint trials and (2) an overall advantage for hint trials will we be in a position to test the interaction predicted in Figure 1.

As an additional check on the effects of sophisticated guessing, we varied bigram frequency. Half of the words had a high bigram frequency, and half had a low bigram frequency. We wanted to include bigram frequency as an additional check for the effects of redundancy. Words with a high bigram frequency are more constrained than words with low bigram frequency. Hence, providing the hint should have less of an effect on high-bigram-frequency words than on low-bigram-frequency words.

\section{EXPERIMENT 1}

\section{Method}

Procedure. On each trial, subjects were presented with two rectangles. One of the rectangles contained a string of five letters; the other contained a string of five pseudoletters. The subject's task was to press either a left or a right arrow key on a keyboard to indicate whether the real letters were in the right or the left rectangle. Subjects had as much time as they wanted in order to respond, and response time was not recorded. Immediately after responding, the subjects were given feedback about the correctness of their response by the computer, which emitted a high-pitched tone for a correct response and a low-pitched tone for an incorrect response.

Each subject participated in at least 30 practice trials, followed by six blocks of 80 trials each. The real letters formed words on 40 trials and nonwords on 40 trials. The order of the stimuli within a block was random, as was the location of the letters and pseudoletters.

On every other block of trials, the word or nonword was also presented at full contrast in the center of the monitor. These were the hint trials. For half of the subjects, the hint trials were run in the evennumbered blocks, and the no-hint trials were run in the odd-numbered block. The remaining subjects received the opposite order.

The contrast of the characters in the rectangles was adjusted during practice with the goal of obtaining between $70 \%$ and $80 \%$ correct. During the experiment, contrast was adjusted between pairs of hint and no-hint blocks, if necessary, in an attempt to maintain $70 \%$
$80 \%$ accuracy. Thus each pair of hint-no-hint blocks had the same contrast.

Stimuli. The stimuli consisted of 40 five-letter words and 40 fiveletter nonwords. The nonwords were anagrams of the words, constructed to be as unlike words as possible (see Appendix). The words were taken from Gernsbacher (1984, Experiments 3 and 4). All of the words were rated as highly familiar. Half of the words had a high bigram frequency and half had a low bigram frequency. The mean summed bigram frequencies of the high- and low-frequency words were 8,395 and 1,069, respectively, according to Massaro, Taylor, Venezky, Jastrzembski, and Lucas (1980).

The stimuli were presented on an Apple 13-in. color monitor controlled by a Macintosh computer. The real letters were presented in Geneva 20-point type. For the pseudoletters, we created a type font that was superficially similar to Geneva, but that of course did not consist of recognizable letters. The pseudoletter strings were also five characters in length. The subjects viewed the displays from approximately $244 \mathrm{~cm}$. The letter and pseudoletter strings subtended approximately $.56^{\circ}$ of visual angle horizontally and $.14^{\circ}$ vertically.

The experimental room was illuminated by standard fluorescent lights. The background of the monitor was white and had a luminance of $122 \mathrm{~cd} / \mathrm{m}^{2}$. The rectangles and hint, when presented, were black and had a luminance of $12 \mathrm{~cd} / \mathrm{m}^{2}$ when measured over an extended area. The letters and pseudoletters were gray and had a mean luminance of $112 \mathrm{~cd} / \mathrm{m}^{2}$ when measured over an extended area (range, $\left.96-116 \mathrm{~cd} / \mathrm{m}^{2}\right)$.

Subjects. Twelve subjects participated in this and each of the experiments reported in this paper. They were recruited from the Psychology Department subject pool at the University of California, Berkeley. The subjects' ages ranged from 18 to 26 years. In the four experiments reported in this paper, 20 of the subjects were male and 28 were female. All the subjects reported normal or corrected-tonormal vision.

\section{Results and Discussion}

As is shown in Figure 3, we were able to meet our two preconditions for testing the sophisticated guessing hypothesis. First, subjects were more accurate with words than with nonwords, $85.9 \%$ versus $81.8 \%$. This effect was reliable both with subjects as the random variable $[F(1,11)$ $=10.10, p<.01]$ and with items as the random variable $[F(1,78)=8.89, p<.01]$. Second, subjects were more accurate when a hint was provided to constrain the letter possibilities, $87.8 \%$ versus $79.9 \%$. This effect was also reliable with both subjects and items as the random variables $[F(1,11)=37.47$ and $F(1,78)=68.52$, respectively, both $p s<.01]$. Despite a significant difference between

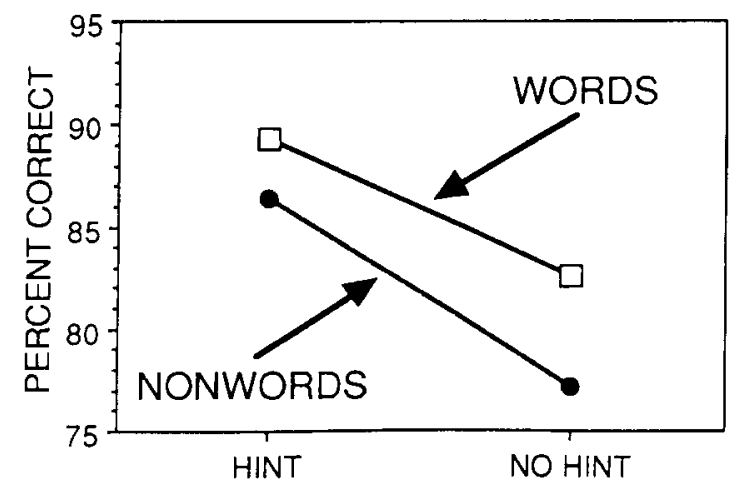

Figure 3. Results of Experiment 1. 
word and nonword conditions, and between hint and nohint conditions, the interaction between these variables did not approach significance. The $F$ ratio of the interaction with subjects as the random variable was $F(1,11)=$ .97 ; with items as the random variable, $F(1,78)=1.60$, n.s. The results for each stimulus item are listed in the Appendix.

We conducted planned comparisons to determine whether the difference between words and nonwords was reliable separately for hint and no-hint trials. On the hint trials, subjects were more accurate with words than with nonwords, $89.4 \%$ versus $86.4 \%$. This difference was reliable both with subjects and with items as the random variable $[t(11)=1.81$ and $t(78)=1.78, p<.05$, onetailed]. Similarly, on the no-hint trials, subjects were more accurate with words than with nonwords, $82.6 \%$ versus $77.2 \%$. This difference was also reliable both with subjects and with items as the random variable $[t(11)=2.73$ and $t(78)=3.09$, respectively, $p<.05$, one-tailed].

In order to determine whether bigram frequency affected performance, we compared high- and low-bigramfrequency words. Subjects were slightly more accurate with high bigram words than with low bigram words, $87.2 \%$ versus $84.7 \%$. However, this difference did not reach conventional significance with subjects as the random variable $[F(1,11)=3.94, .10>p>.05]$ or with items as the random variable $[F(1,38)=3.1, .20>p>.10]$. With the word stimuli, bigram frequency did not significantly interact with whether or not a hint was provided, either with subjects or with items as the random variable (both $F \mathrm{~s}<1.0$ ).

In Experiment 1, we were successful in obtaining a word-detection effect. We also have evidence that subjects were using the information that we provided on hint trials to constrain the letter possibilities and thus improve their performance. Yet the word-detection effect was not significantly less on hint trials than on no-hint trials, contrary to the prediction of the sophisticated guessing hypothesis.

\section{EXPERIMENT 2}

One possible reason that the word-detection effect was as great in the hint trials as in the no-hint trials is that the information given by the hints might not have been the same type of information that caused word performance to be greater than nonword performance. It has been argued that much of the information that distinguishes word from nonword processing resides in abstract letter codes rather than physical graphemic codes (see, e.g., Besner \& Johnston, 1989; McClelland, 1976; Paap, Newsome, \& Noel, 1984; see also Prinzmetal, Hoffman, \& Vest, 1991). Subjects could have used information from the physical contours of the hint to match the low-contrast stimuli without necessarily processing the hints at an abstract letter level. Thus the benefit that was provided by the hints would be the same for words and for nonwords, since the sequence of letters would have nothing to do with the hint effect.

\section{Method}

In order to make it unlikely that subjects were using the hints simply to match physical contours with the stimuli, in Experiment 2 we selected a font for the hints that was quite dissimilar to the font used for the letters and pseudoletters. The letters and pseudoletters were the same as in Experiment 1, but the hints were presented in 36-point Malibu type (see Figure 4). In all other respects, Experiment 2 was identical to Experiment 1 .

\section{Results and Discussion}

The results are shown in Figure 5. As in Experiment 1, subjects were more accurate with words than with nonwords, $88.2 \%$ versus $83.2 \%$. This effect was reliable with both subjects and items as the random variable $[F(1,11)=$ 30.84 and $F(1,78)=16.06$, respectively, both $p$ s $<.01$ ] Also, subjects were more accurate when a hint was provided than when no hint was provided, $87.2 \%$ versus $84.2 \%$. This effect, although smaller than in Experiment 1 (see the discussion below), was also reliable with both subjects and items as the random variable $[F(1,11)=$ 6.38 and $F(1,78)=8.06$, respectively, both $p$ s $<.05]$. Finally, as in Experiment 1, the interaction between these two variables did not approach significance with either subjects or items as the random variable $[F(1,11)=0.15$ and $F(1,78)=0.89$, respectively].

As in Experiment 1, considering only the hint condition, subjects were more accurate with words than with nonwords, $89.4 \%$ versus $84.9 \%$. This difference was reliable by a planned comparison with both subjects and items as the random variables $[t(11)=3.14$ and $t(78)=$ 2.89 , respectively, both $p s<.05]$. In the no-hint condition, subjects were also more accurate with words than with nonwords $[86.9 \%$ vs. $81.5 \% ; t(11)=3.68$ and $t(78)=$ 3.28 , both $p s<.05]$. Thus, in Experiments 1 and 2, the hint affected overall performance, but it did not significantly affect the difference between words and nonwords.

We examined the word trials for an effect of bigram frequency. The average percents correct for high and low

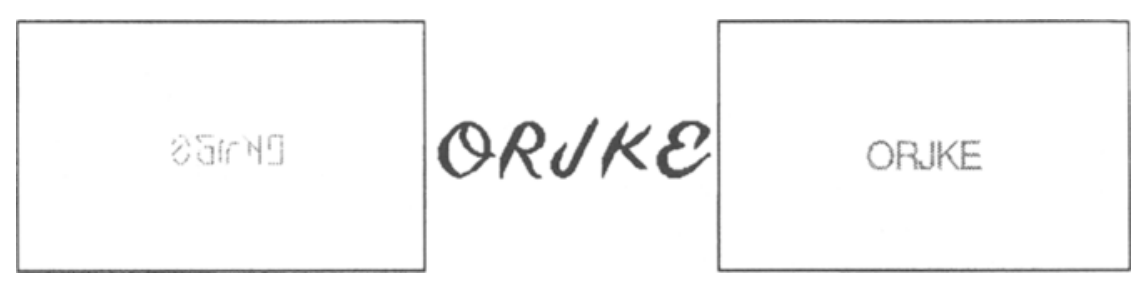

Figure 4. Sample nonword stimulus from Experiment 2. 


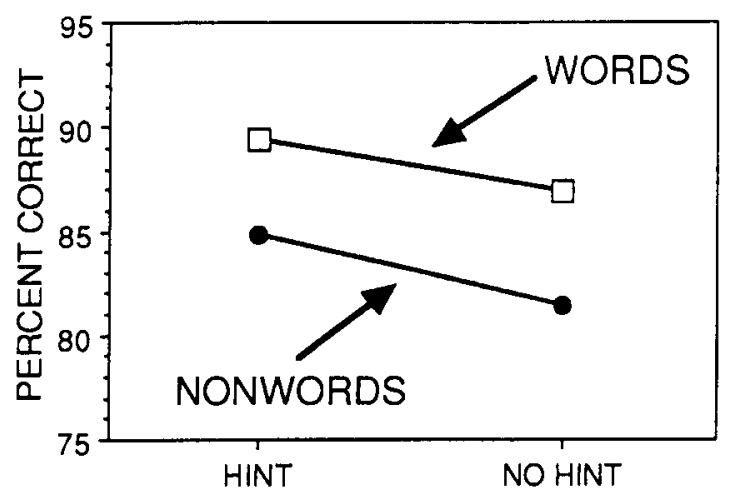

Figure 5. Results of Experiment 2.

bigram words were $88.1 \%$ and $88.3 \%$, respectively, and did not approach significance with either subjects or items as the random variable. Furthermore, bigram frequency did not interact with any other variable.

As in Experiment 1, we found a significant worddetection effect and significant effect of hints, but no interaction. The difference between words and nonwords was not reduced when subjects knew exactly what letters would appear in the stimulus. This finding is counter to the predictions of the sophisticated guessing hypothesis.

The effect of the hint in Experiment 2 was about half of what it was in Experiment 1. We confirmed that the hint effect was smaller in Experiment 2 by conducting an analysis of variance with experiment as a betweensubjects factor (Experiment 1 vs. Experiment 2). In this analysis, the interaction of the hint effect and experiment was reliable with both subjects and items as the random variable $[F(1,22)=8.18$ and $F(1,78)=15.96$, both $p s<$ $.05]$.

There are at least two explanations for this reduction in the hint effect. First, it may be that the effect of the hint in Experiment 1 had two components. Subjects were matching physical features of the hint to the stimulus strings and they were also using information about the sequences of letter identities to constrain letter possibilities. In Experiment 2, there was little to be gained by matching the physical features of the hint to the stimuli, and what remained was a pure effect of knowledge of letter alternatives.

Second, it may be that subjects were using only abstract letter identity to constrain the letter possibilities in both experiments. However, in Experiment 2, subjects did not use this information as often as they did in Experiment 1, because the hints looked very different from the stimuli. In effect, in Experiment 2, subjects might not have bothered to read the hints on some of the trials and this reduced the hint effect. These two explanations are not mutually exclusive, of course. In Experiment 3, we wanted to see what would happen if on each trial we forced subjects to pay attention to the hints before they identified the rectangle containing the letters.

\section{EXPERIMENT 3}

\section{Method}

Experiment 3 was similar to Experiment 2. Subjects had to determine which of two rectangles contained letters and which contained pseudoletters. In every other block of trials, the word or pseudoword was also presented between the rectangles to provide subjects with a hint as to the identity of the letters. As in Experiment 2, the hint was written in Malibu 36-point type. Experiment 3 differed from Experiment 2 only in the following manner. On hint trials, before subjects responded with which rectangle contained the real letters, they had to report whether the hint was a word or a nonword. This was, of course, a trivially easy task, but it served to ensure that subjects were paying attention to the hints. If the hint was a word, subjects were to press the "up" arrow key; if it was a nonword, they were to press the "down" arrow key. There were rarely any mistakes at this task. On the rare occasion when a subject made an error at this task, the computer made a sound somewhat like that of a foghorn. After indicating whether the hint was a word or a nonword, subjects indicated which rectangle contained the letters.

\section{Results and Discussion}

The results, illustrated in Figure 6, are remarkably similar to the results of the previous experiments. Subjects were more accurate with words than with nonwords, $88.8 \%$ versus $81.3 \%$, respectively, and this effect was reliable with both subjects and items as the random factor $[F(1,11)=75.03$ and $F(1,78)=29.09$, both $p s<.01]$. Subjects were significantly more accurate on hint trials than on no-hint trials, $86.9 \%$ versus $83.3 \%$. The effect of providing a hint was reliable with both subjects and items as the random variable $[F(1,11)=4.80$ and $F(1,78)=$ 13.65 , both $p \mathrm{~s}<.05]$. However, the interaction of these factors was not reliable with either subjects or items as the random variable (both $F_{\mathrm{s}}<1.0$ ).

As in the previous experiments, we compared words and nonwords separately for the hint and no-hint trials. On the hint trials, subjects were significantly more accurate with words than with nonwords, $90.6 \%$ versus $83.1 \%$. This difference was reliable with both subjects and items as the random variables $[t(11)=7.88$ and $t(78)=$ 5.43 , respectively, both $p s<.05]$. On the no-hint trials also, subjects were more accurate with words than with nonwords, $87.0 \%$ and $79.5 \%[t(11)=5.89$ and $t(78)=$ 3.81 , both $p \mathrm{~s}<.05$ ].

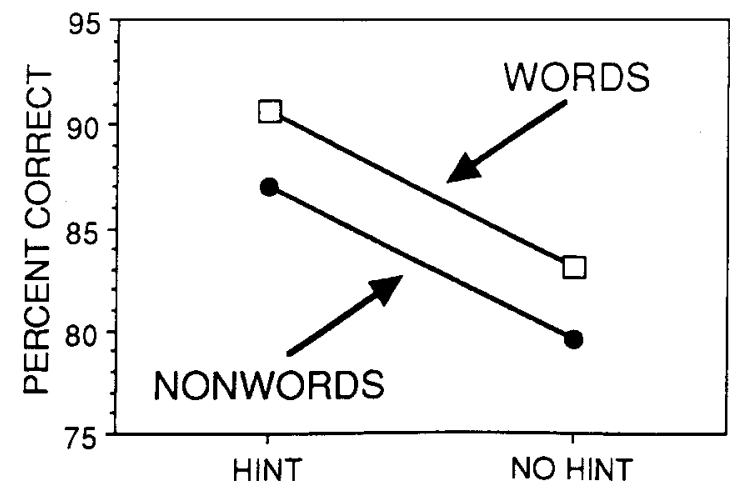

Figure 6. Results of Experiment 3. 
Overall, the effect of bigram frequency was not reliable with either subjects or items as the random factor (both $F \mathrm{~s}<1.0$ ). However, there was a suggestion of an interaction of bigram frequency and the hint effect when subjects was the random variable. With high-bigramfrequency words, accuracy on hint and no-hint trials was $91.9 \%$ and $86.1 \%$, respectively. For low-bigram-frequency words, the accuracy on hint and no-hint trials was $89.3 \%$ and $87.1 \%$. Thus the effect of providing explicit constraints was greater with high-bigram-frequency words than with low-bigram-frequency words. This interaction was reliable for items as the random variable $[F(1,38)=4.70]$ but not with subjects as the random variable $[F(1,11)=$ $1.81, .25>p>.20$ ]. It is important to note that this interaction is in the direction opposite that predicted by sophisticated guessing. Sophisticated guessing predicts that the effect of a hint should be less with high-bigramfrequency words, because with these words, possible letter sequences are already constrained by orthography. However, the interaction between bigram frequency and the hint effect was only reliable in this experiment, and the interaction was only significant with items as the random factor, so perhaps not too much importance should be given to this finding.

In Experiments 1-3, we failed to find the interaction predicted by sophisticated guessing: Explicit knowledge of possible letters did not decrease the difference in performance between words and nonwords. However, the predicted interaction may have not been significant because individual experiments lacked sufficient power. By combining the data in Experiments 1-3, we had a much more powerful design ( 36 subjects vs. 12 subjects). In this analysis, subjects (the random factor) were nested in experiment. The word advantage did not interact with the hint effect $[F(1,33)=.82]$. In summary, in three experiments subjects were better at discriminating letters from pseudoletters when those letters spelled a word than when they spelled a nonword. Furthermore, when we provided a hint that exactly constrained what letters would appear, subjects were still significantly more accurate with words than with nonwords.

\section{EXPERIMENT 4}

\section{Method}

In the final experiment, we wanted to create a situation in which the hint and the stimuli were even more physically dissimilar than they were in Experiments 2 and 3, to further ensure that subjects were not utilizing the hint by matching physical codes but rather using the hint to constrain possible letters. To do this, we presented the letters and pseudoletters in a vertical orientation. Marchetti and Mewhort (1986) found that presenting stimuli in a vertical orientation eliminated a robust advantage for words over single letters in the Reicher task. However, Krueger (1975) found an advantage of words over nonwords with a vertical orientation (also see Prinzmetal et al., 1991). In any case, the sophisticated guessing hypothesis clearly predicts that if we obtain a word-detection effect, it should be larger in the no-hint condition than in the hint condition.

The stimuli in Experiment 4 were exactly like those in Experiment 3, except that they were vertically oriented (see Figure 7). As in Experiment 3, subjects were required to classify the hints as words or nonwords before indicating which rectangle contained the letters.

\section{Results and Discussion}

The results are shown in Figure 8. For the first time in this research, there appeared to be an interaction between the word advantage and the effect of a hint. The interaction shown in Figure 8 was reliable with items as the random factor $[F(1,78)=37.06, p<.01]$ and just missed the conventional significance level with subjects as the random variable $[F(1,11)=4.04, .05<p<.07]$. Note, however, that the effect of the hint is in the opposite direction of that predicted by the sophisticated guessing hypothesis. When subjects were given a hint that constrained the possible letters, they were significantly more accurate with words than with nonwords, $86.2 \%$ versus $80.6 \%$ $[t(11)=2.77$ and $t(78)=3.55$, both $p s<.05$, for the subject and item analyses, respectively]. However, when the hint was not provided, there was no significant difference in accuracy between words and nonwords, $77.0 \%$ versus $76.7 \%[t(11)=0.14$ and $t(78)=0.17$, both n.s. $]$. Some factor other than sophisticated guessing must have been responsible for this interaction. In the analysis of words, bigram frequency did not significantly affect accuracy with words or items as the random variable, nor did it significantly interact with any other variable (all $F$ ratios $<1.0$ with subjects and items as the random variable).

The larger word-detection effect following a hint is consistent with recent findings of Chastain and Ferraro (1995) using the Reicher task. Subjects first engaged in a task in which they classified stimuli as nouns, verbs, or nonwords. In a subsequent experiment, the word-superiority effect was larger with stimuli previously classified by subjects than it was for new stimuli. In other words, priming the stimulus increased the word-superiority effect. Both the present results and those of Chastain and Ferraro can be readily understood in terms of lexical theories of the word advantage. For example, according to McClelland and Rumelhart (1981), the word advantage is due to

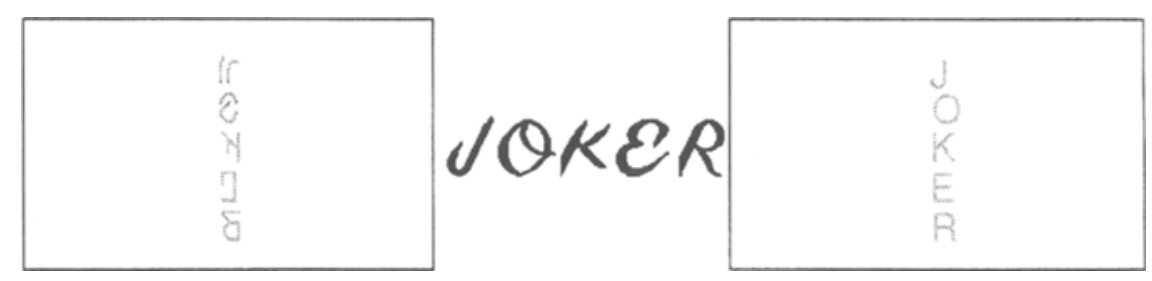

Figure 7. Sample word stimulus from Experiment 4. 


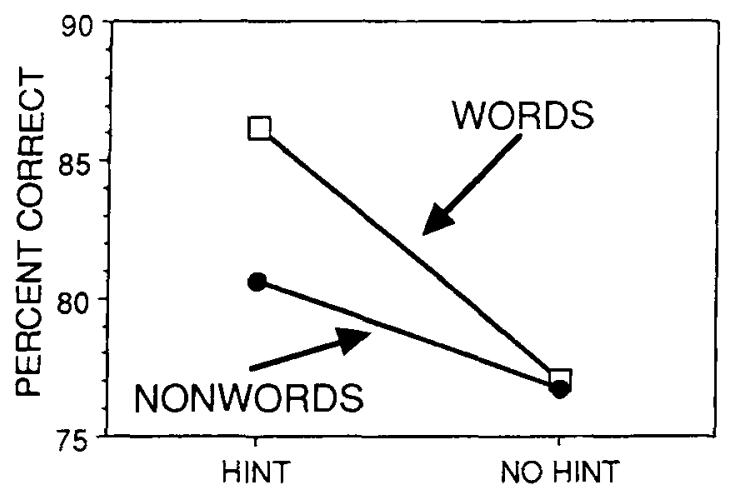

Figure 8. Results of Experiment 4.

feedback from the lexicon to the letter representation. If the lexical item is primed, it should provide a greater influence on letter perception than if it is not primed. However, these results are also consistent with the possibility that the hint primes familiar orthgraphic patterns or even orthographic rules.

The results of Experiment 4 demonstrate that subjects have a certain amount of flexibility in how they process word stimuli. On the one hand, on no-hint trials subjects could have treated words as a collection of individual letters. With this strategy, subjects would have scrutinized each character position in order to determine whether it contained a letter or a pseudoletter. With this processing strategy, words and nonwords would not have differed. On the other hand, on hint trials, subjects might have been induced to process the words as words, leading to a word-detection effect. There is a precedent for strategic factors in the word-superiority effect. Johnston and McClelland (1974), in an article creatively titled "Seek Not and Ye Shall Find," observed that with word stimuli, when subjects were instructed to attend to the target position, they were less accurate than when they were instructed to spread their attention over all of the letters in the word (cf. Carr, Davidson, \& Hawkins, 1978). Thus, attention to individual letters in words would have caused performance to be worse than when subjects attended to the letter string as a whole.

The strategic effect of attending to word wholes as opposed to individual letters many explain some inconsistent findings. For example, as noted previously, Krueger (1975) found a word-superiority effect when he used stimuli with a vertical orientation, but Marchetti and Mewhort (1986) found that vertical orientation eliminated a robust advantage for words over single letters. McClelland (1976) found that mixing case did not affect the word-superiority effect, but Mewhort and Johns (1988) found that mixing case eliminated the word advantage. There are other examples of such inconsistent findings in the literature. In each of these examples, some stimulus variable reduced or eliminated the word advantage. The question that should be asked is whether the stimulus variable in question biases subjects against processing the stimuli as words, or whether it makes it impossible for subjects to process the stimuli as words. In Experiment 4, vertical orientation biased subjects not to process words as such, but the hint induced word processing.

\section{GENERAL DISCUSSION}

In the present research we tested the sophisticated guessing hypothesis that has been proposed to account for the word-detection effect. The hypothesis is that the possible letter sequences in words are constrained by English orthography, but that the letters in nonwords are not constrained in this manner. In the hint condition, we equated the information on possible letter sequences in words and nonwords by explicitly informing subjects which letter sequence would be present in the words or the nonwords. Counter to the sophisticated guessing hypothesis, in three experiments, providing a hint did not affect the magnitude of the word advantage. In the final experiment, providing the hint did affect magnitude of the word advantage but in the direction opposite that predicted by the sophisticated guessing hypothesis: Performance was better with words than with nonwords only when subjects were given a hint.

Although we could not find evidence in support of the sophisticated guessing hypothesis, it would perhaps be hasty to embrace the null hypothesis. Explicit knowledge of the letter alternatives may play a role in the word advantage in some circumstances. However, it is clear that explicit knowledge of the alternatives cannot be the only cause of the word advantage. In the hint condition of each experiment, subjects were significantly more accurate with words than with nonwords. Thus subjects explicitly knew what word or nonword to expect, yet they still discriminated letters from pseudoletters more accurately in words than in nonwords. Furthermore, unlike in previous research, we have good evidence that the subjects were actually using the information provided by the hints.

The present experiments demonstrate that some component of the word advantage must be caused by perceptual as opposed to decision mechanisms. There are of course numerous theories of the word-superiority effect that are suited to account for the word-detection effect. The theories can be distinguished from one another on the basis of (1) the type of information used by the perceptual system to help process words, and (2) the type of algorithm used for processing this information. The theories of McClelland and Rumelhart (1981) and Paap et al. (1982), for example, both propose that information from the lexicon causes the word advantage. Richman and Simon (1989) and Mozer (1984, cited in McClelland \& Mozer, 1986) proposed that familiar spelling patterns provide the information that leads to better processing for words than for nonwords (cf., e.g., Massaro et al., 1981; Massaro et al., 1979; Venezky \& Massaro, 1987). In terms of algorithms, McClelland and Rumelhart (1981) and Mozer (1984) use parallel distributed networks, while Richman and Simon (1989) use a production system. Unfortunately, the present experiments did not distinguish among these perceptual theories. However, as a result of 
the present work, we can assert that explicit knowledge of the alternatives can improve performance, but that it does not eliminate the word advantage.

If letters in words are more accurately perceived than letters in nonwords, one might expect perceptual consequences other than the word-superiority and worddetection effects. For example, in addition to the wordsuperiority effect, there is a letter-superiority effect: Subjects are more accurate at identifying a line segment when it is part of a letter than when it is part of a pseudoletter (Schendel \& Shaw, 1976). Recently, Reingold and Jolicoeur (1993) found that subjects could also identify the color of letters better than pseudoletters. Jolicoeur (personal communication, July 1993) also found that these results extended to words and nonwords. Subjects are more accurate at identifying the color of letters when the letters form a word than when they form a nonword (cf. Prinzmetal et al., 1991; Prinzmetal \& Millis-Wright, 1984). The perceptual enhancement of a stimulus attribute uncorrelated with the identity of the target letter or pseudoletter cannot be explained by decision processes, such as those proposed by the sophisticated guessing hypothesis.

In summary, the sophisticated guessing hypothesis predicted that knowledge of the possible letter sequence before a trial should eliminate the word advantage. We tested this prediction with the word-detection effect. Although foreknowledge of the letter sequences did improve performance, the improvement in performance was no greater for nonwords than for words.

\section{REFERENCES}

Besner, D., \& Johnston, J. C. (1989). Reading and the mental lexicon On the uptake of visual information. In W. Marslen-Wilson (Ed.), Lexical representation and process (pp. 291-316). Cambridge, MA: MIT Press.

BJORK, E. L., \& EsTES, W. K. (1973). Letter identification in relation to linguistic context and masking conditions. Memory \& Cognition, 1 , 217-223.

Carr, T. H., Davidson, B. J., \& Hawkins, H. L. (1978). Perceptual flexibility in word recognition: Strategies affect orthographic computation but not lexical assess. Journal of Experimental Psychology: Human Perception \& Performance, 4, 674-690.

Carr, T. H., \& Pollatsek, A. (1985). Recognition of printed words: A look at current models. In D. Besner, T. G. Waller, \& G. E. Mackinnon (Eds.), Reading research: Advances in theory and practice (Vol. 5 , pp. 1-82). New York: Academic Press.

Cattell, J. M. (1885). The inertia of the eye and brain. Brain, 8, 295 312 .

Cattell, J. M. (1886a). The time it takes to see and name objects. Mind, $11,63-65$.

Cattell, J. M. (1886b). The time taken up by cerebral operations. Mind, 11, 377-387.

Chastain, G., \& Ferraro, F. R. (1995). Is lexical access involved in the Reicher task? Manuscript in preparation.

Dixon, P. (1986). Attention and interference in the perception of brief visual displays. Joumal of Experimental Psychology: Human Perception \& Performance, 12, 133-148.

DOYLE, J. R., \& LEACH, C. (1988). Word superiority in signal detection: Barely a glimpse, yet reading nonetheless. Cognitive Psychology, 20, 283-318.

ESIES, W. K., BJork, E. L., \& SKaAR, E. (1974). Detection of single letters and letters in words with changing vs unchanging mask characters. Bulletin of the Psychonomic Society, 3, 201-203.
FoDOR, J. A. (1984). The modularity of mind. Cambridge, MA: MIT Press.

GERNSBACHER, M. A. (1984). Resolving 20 years of inconsistent interactions between lexical familiarity and orthography, concreteness, and polysemy. Journal of Experimental Psychology: General, 113, 256-281.

HOLENDER, D. (1979). Identification of letters in words and of single letters with pre- and postknowledge vs. postknowledge of the alternatives. Perception \& Psychophysics, 25, 313-318.

JOHNSTON, J. C. (1978). A test of the sophisticated guessing theory of word perception. Cognitive Psychology, 10, 123-153.

JOHNSTON, J. C. (1981). Effects of advance precuing of alternatives on the perception of letters alone and in words. Journal of Experimental Psychology: Human Perception \& Performance, 7, 560-572.

Johnston, J. C., \& MCClelland, J. L. (1974). Perception of letters in words: Seek not and ye shall find. Science, 184, 1192-1194.

KRUEGER, L. E. (1975). The word-superiority effect: Is its locus visualspatial or verbal? Bulletin of the Psychonomic Society, 6, 465-468.

MARCHETTI, F. M., \& MEWHORT, D. J. K. (1986). On the word-superiority effect. Psychological Research, 48, 23-35.

Massaro, D. W. (1973). Perception of letters, words, and nonwords. Journal of Experimental Psychology, 100, 349-353.

Massaro, D. W., Jastrzembski, J. E., \& Lucas, P. A. (1981). Frequency, orthographic regularity, and lexical status in letter and word perception. In G. H. Bower (Ed.), The psychology of learning and motivation (Vol. 15, pp. 163-200). London: Academic Press.

Massaro, D. W., Taylor, G. A., Venezky, R. L., Jastrzembski, J. E., \& LuCAS, P. A. (1980). Letter and word perception: The role of orthographic structure and visual processing in reading. Amsterdam: NorthHolland.

Massaro, D. W., Venezky, R. L., \& Taylor, G. A. (1979). Orthographic regularity, positional frequency, and visual processing of letter strings. Journal of Experimental Psychology: General, 108, 107-124.

MCCleLland, J. L. (1976). Preliminary letter identification in the perception of words and nonwords. Journal of Experimental Psychology: Human Perception \& Performance, 2, 80-91.

McClelland, J. L., \& Mozer, M. C. (1986). Perceptual interactions in two-word displays. Journal of Experimental Psychology: Human Perception \& Performance, 12, 18-35.

McClelland, J. L., \& Rumelhart, D. E. (1981). An interactive activation model of context effects in letter perception: Part 1. An account of basic findings. Psychological Review, 88, 375-407.

Merikle, P. M., \& Reingold, E. M. (1990). Recognition and lexical decision without detection: Unconscious perception. Journal of Experimental Psychology: Human Perception \& Performance, 16, 574583.

MEWhorT, F. M., \& JohNs, E. E. (1988). Some tests of the interactiveactivation model for word identification. Psychological Research, 50, 135-147.

NEILL, W. T. (1985). Levels of processing in disruptive effects of prior information. Memory \& Cognition, 13, 477-484.

Paap, K. R., Newsome, S. L., McDonald, J. E., \& Schvaneveldt, R. W. (1982). An activation-verification model for letter and word recognition: The word-superiority effect. Psychological Review, 89, 573-594

PaAp, K. R., Newsome, S. L., \& Noel, R. W. (1984). Word shape in poor shape for the race to the lexicon. Journal of Experimental Psychology: Human Perception \& Performance, 10, 413-428.

PRINZMETAL, W. (1992). The word-superiority effect does not require a T-scope. Perception \& Psychophysics, 51, 473-484.

Prinzmetal, W., Hoffman, H., \& Vest, K. (1991). Automatic processes in word perception: An analysis from illusory conjunctions. Journal of Experimental Psychology: Human Perception \& Performance, 17, 902-923.

Prinzmetal, W., \& Millis-Wright, M. (1984). Cognitive and linguistic factors affect visual feature integration. Cognitive Psychology, 16, 305-340.

Prinzmetal, W., \& Silvers, B. (1994). The word without the tachistoscope. Perception \& Psychophysics, 55, 296-312.

Purcell, D. G., \& Stanovich, K. E. (1982). Some boundary conditions for a word superiority effect. Quarterly Journal of Experimental Psychology, 34A, 117-134. 
Purcell, D. G., Stanovich, K. E., \& Spector, A. (1978). Visual angle and the word superiority effect. Memory \& Cognition, 6, 3-8.

PYlyshyn, Z. (1980). Computation and cognition: Issues in the foundation of cognitive science. Behavioral \& Brain Sciences, 3, 111-132.

ReICHER, G. M. (1969). Perceptual recognition as a function of meaningfulness of stimulus material. Journal of Experimental Psychology, 81, 275-280.

Reingold, E. M., \& Jolicoevr, P. (1993). Perceptual versus postperceptual mediation of visual context effects: Evidence from the lettersuperiority effect. Perception \& Psychophysics, 53, 166-178.

Richman, H. B., \& SimON, H. A. (1989). Context effects in letter perception: Comparison of two theories. Psychological Review, 96, 417-432.

Schendel, J. D., \& Shaw, P. (1976). A test of the generality of the word-context effect. Perception \& Psychophysics, 19, 383-393.

Smith, E. E., \& HaviLAND, S. E. (1972). Why words are perceived more accurately than nonwords: Inference versus unitization. Journal of Experimental Psychology, 92, 59-64.

Smith, E. E., Reder, L. M., Haviland, S. E., \& Brownell, H. (1976).
When preparation fails: Disruptive effects of prior exposure on perceptual recognition. Journal of Experimental Psychology: Human Perception \& Performance, 2, 151-161.

Solman, R. T., May, J. G., \& Schwartz, B. D. (1981). The word superiority effect: A study using parts of letters. Journal of Experimental Psychology: Human Perception \& Performance, 7, 552-559. Thompson, M. C., \& MASSARo, D. W. (1973). Visual information and redundancy in reading. Journal of Experimental Psychology, 98, 49-54.

VENEZKY, R. L., \& MASSARO, D. W. (1987). Orthographic structure and spelling-sound regularities in reading English. In A. Allport, D. MacKay, W. Prinz, \& E. Scheerer (Eds.), Language perception and production (pp. 111-129). London: Academic Press.

\section{NOTE}

1. We do not wish to suggest that Cattell was the only researcher working on these effects. Some of Cattell's work was based on work conducted by Wundt, Wundt's students, and others.

APPENDIX

\begin{tabular}{|c|c|c|c|c|c|c|c|c|}
\hline \multirow[b]{3}{*}{ Stimuli } & \multicolumn{8}{|c|}{ Experiment } \\
\hline & \multicolumn{2}{|c|}{1} & \multicolumn{2}{|c|}{2} & \multicolumn{2}{|c|}{3} & \multicolumn{2}{|r|}{4} \\
\hline & Hint & No Hint & Hint & No Hint & Hint & No Hint & Hint & No Hint \\
\hline \multicolumn{9}{|c|}{ High Bigram Words } \\
\hline SUPER & .917 & .861 & .917 & .944 & .917 & .833 & .833 & .861 \\
\hline CHILI & .889 & .889 & .917 & .806 & .972 & .861 & .833 & .806 \\
\hline ROACH & .944 & .778 & .944 & .750 & .889 & .889 & .889 & .750 \\
\hline ICING & .667 & .750 & .778 & .889 & .806 & .833 & .833 & .694 \\
\hline JOKER & .944 & .778 & .944 & .889 & .889 & .861 & .917 & .806 \\
\hline ULCER & .861 & .889 & .806 & .972 & .917 & .889 & .889 & .750 \\
\hline BOXER & .889 & .889 & .917 & .861 & .944 & .944 & .889 & .917 \\
\hline CHORE & .972 & .861 & .972 & .972 & .972 & .917 & .861 & .750 \\
\hline MIXER & .861 & .750 & .972 & .806 & .889 & .806 & .889 & .833 \\
\hline LOUSY & .944 & .861 & .917 & .861 & .833 & .917 & .806 & .833 \\
\hline STALE & .889 & .806 & .778 & .917 & .944 & .806 & .861 & .694 \\
\hline PRONG & .972 & .889 & .806 & .861 & .917 & .889 & .750 & .750 \\
\hline BELCH & .972 & .778 & .917 & .972 & .917 & .889 & .889 & .861 \\
\hline BATCH & .944 & .889 & .917 & .889 & .917 & .889 & .833 & .750 \\
\hline BOOST & .889 & .833 & .972 & .806 & .944 & .806 & .833 & .778 \\
\hline RACER & .944 & .944 & .861 & .917 & .972 & .861 & .889 & .667 \\
\hline RHINO & .861 & .694 & .750 & .694 & .889 & .778 & .889 & .750 \\
\hline LEACH & .972 & .861 & .944 & .861 & .100 & .833 & .889 & .722 \\
\hline CHESS & .917 & .889 & .944 & .889 & .917 & .806 & .944 & .722 \\
\hline CIDER & .944 & .778 & .889 & .806 & .944 & .917 & .917 & .806 \\
\hline \multicolumn{9}{|c|}{ Low Bigram Words } \\
\hline BOOZE & .917 & .833 & .750 & .861 & .917 & .917 & .833 & .806 \\
\hline FUDGE & .889 & .889 & .861 & .889 & .889 & .917 & .806 & .889 \\
\hline AMAZE & .944 & .750 & .944 & .778 & .861 & .750 & .889 & .722 \\
\hline BANJO & .833 & .861 & .889 & .861 & .861 & .833 & .778 & .750 \\
\hline ALBUM & .889 & .833 & .917 & .917 & .972 & .917 & .972 & .833 \\
\hline BURNS & .889 & .694 & .917 & .944 & .889 & .917 & .833 & .833 \\
\hline DENIM & .806 & .806 & .100 & .750 & .972 & .889 & .806 & .694 \\
\hline BULKY & .861 & .833 & .972 & .833 & .889 & .100 & .833 & .861 \\
\hline KODAK & .917 & .833 & .917 & .833 & .861 & .861 & .944 & .833 \\
\hline SOAPY & .861 & .806 & .861 & .889 & .806 & .778 & .889 & .833 \\
\hline SISSY & .889 & .694 & .833 & .778 & .667 & .806 & .667 & .694 \\
\hline JERKY & .889 & .806 & .833 & .917 & .944 & .944 & .944 & .833 \\
\hline TULIP & .750 & .750 & .889 & .917 & .833 & .833 & .889 & .667 \\
\hline PUFFY & .944 & .889 & .917 & .917 & .944 & .944 & .889 & .806 \\
\hline FUNGI & .806 & .778 & .778 & .889 & .833 & .778 & .889 & .722 \\
\hline SUEDE & .889 & .833 & .861 & .889 & .917 & .889 & .889 & .806 \\
\hline ULTRA & .917 & .833 & .972 & .778 & .972 & .861 & .861 & .694 \\
\hline BAGGY & .778 & .889 & .861 & .861 & .944 & .833 & .778 & .694 \\
\hline BLUFF & .972 & .889 & .944 & .944 & .917 & .944 & .806 & .583 \\
\hline EXCEL & .889 & .861 & .100 & .972 & .972 & .972 & .944 & .750 \\
\hline
\end{tabular}


Appendix (Continued)

\begin{tabular}{|c|c|c|c|c|c|c|c|c|}
\hline \multirow[b]{3}{*}{ Stimuli } & \multicolumn{8}{|c|}{ Experiment } \\
\hline & \multicolumn{2}{|r|}{1} & \multicolumn{2}{|r|}{2} & \multicolumn{2}{|c|}{3} & \multicolumn{2}{|r|}{4} \\
\hline & Hint & No Hint & Hint & No Hint & Hint & No Hint & Hint & No Hint \\
\hline \multicolumn{9}{|c|}{ Nonwords } \\
\hline UEPSR & .972 & .833 & .806 & .806 & .917 & .889 & .889 & .833 \\
\hline ICIHLI & .778 & .667 & .861 & .806 & .861 & .639 & .889 & .917 \\
\hline HRCAO & .889 & .861 & .750 & .833 & .833 & .722 & .833 & .806 \\
\hline IGCNI & .667 & .667 & .750 & .639 & .806 & .611 & .750 & .611 \\
\hline ORJKE & .861 & .889 & .889 & .889 & .778 & .889 & .806 & .750 \\
\hline UCERL & .833 & .944 & .750 & .806 & .972 & .861 & .806 & .750 \\
\hline RXEBO & .917 & .694 & .917 & .861 & .861 & .806 & .806 & .722 \\
\hline HCEOR & .944 & .750 & .889 & .861 & .833 & .861 & .889 & .889 \\
\hline EXRMI & .889 & .722 & .972 & .806 & .861 & .833 & .694 & .750 \\
\hline UYSLO & .778 & .833 & .861 & .917 & .889 & .639 & .833 & .694 \\
\hline ETSLA & .917 & .917 & .972 & .944 & .861 & .889 & .833 & .778 \\
\hline GNRPO & .833 & .722 & .694 & .750 & .750 & .722 & .806 & .833 \\
\hline EHLBC & .917 & .778 & .806 & .917 & .889 & .917 & .778 & .861 \\
\hline ABHTC & .833 & .806 & .889 & .722 & .806 & .917 & .861 & .889 \\
\hline OOBTS & .806 & .806 & .778 & .806 & .944 & .806 & .861 & .806 \\
\hline RCREA & .972 & .944 & .833 & .806 & .778 & .861 & .889 & .833 \\
\hline NRHOI & .806 & .611 & .750 & .639 & .750 & .667 & .667 & .833 \\
\hline HCLAE & .917 & .694 & .917 & .917 & .806 & .889 & .917 & .806 \\
\hline CSSEH & .861 & .611 & .722 & .806 & .889 & .778 & .833 & .750 \\
\hline ERDCI & .889 & .750 & .889 & .889 & .806 & .944 & .889 & .694 \\
\hline OOEZB & .750 & .861 & .889 & .778 & .778 & .722 & .833 & .806 \\
\hline UGCFE & .889 & .667 & .917 & .861 & .861 & .833 & .917 & .750 \\
\hline ZMAEA & .917 & .694 & .944 & .694 & .722 & .556 & .861 & .694 \\
\hline NBJOA & .889 & .778 & .750 & .778 & .806 & .833 & .750 & .722 \\
\hline MLUAB & .861 & .778 & .889 & .778 & .833 & .694 & .889 & .722 \\
\hline NRBSU & .778 & .667 & .861 & .806 & .806 & .667 & .778 & .722 \\
\hline IDMNE & .833 & .694 & .750 & .778 & .778 & .667 & .778 & .750 \\
\hline UYBKL & .889 & .778 & .778 & .917 & .806 & .806 & .778 & .750 \\
\hline OKADK & .861 & .833 & .889 & .944 & .833 & .944 & .833 & .806 \\
\hline OPYSA & .944 & .750 & .833 & .694 & .806 & .639 & .750 & .778 \\
\hline SYSSI & .583 & .667 & .833 & .778 & .722 & .611 & .583 & .583 \\
\hline EKYRJ & .944 & .861 & .944 & .889 & .889 & .778 & .778 & .806 \\
\hline TPLUI & .861 & .861 & .861 & .833 & .806 & .861 & .778 & .667 \\
\hline UYPFF & .889 & .722 & .833 & .750 & .778 & .889 & .778 & .833 \\
\hline IUNFG & .806 & .667 & .861 & .722 & .750 & .778 & .583 & .806 \\
\hline EEUDS & .972 & .806 & .944 & .750 & .889 & .917 & .833 & .806 \\
\hline TLRAU & .861 & .806 & .833 & .861 & .889 & .833 & .750 & .778 \\
\hline BGGYA & .861 & .750 & .806 & .750 & .778 & .861 & .694 & .611 \\
\hline FFLBU & .917 & .833 & .917 & .833 & .917 & .806 & .861 & .667 \\
\hline ELXCE & .972 & .917 & .917 & .972 & .917 & .972 & .889 & .833 \\
\hline
\end{tabular}

(Manuscript received August 16, 1994;

revision accepted for publication February 16, 1995.) 